\title{
A Comparative Study to Assess the Level of Leadership Behaviour and Empowerment, its Effect on Burnout among Staff Nurses from Selected Government and Private Hospitals of Pune City
}

\author{
Sundari Apte ${ }^{1}$, Dr. T. Bhattacharjee ${ }^{2}$ \\ ${ }^{1}$ M.Sc. Mental Health Nursing, pursuing PhD in Nursing, Bharati Vidyapeeth College of Nursing Pune, Maharashtra, India \\ ${ }^{2}$ Guide, Bharati Vidyapeeth College of Nursing Pune
}

\begin{abstract}
Leadership among the nurses is a very important desired quality and being female dominated they should feel empowered and how these two affect their burnout in their services was the key aspect of interest and to compare the study between government and private sector nurses The objectives of the study was i) To assess the leadership behaviour, burnout and empowerment level among staff nurses; ii)To compare the leadership behaviour, burnout level and empowerment level between the nurses from government and private hospital; iii)To assess the correlation between the leadership behaviour, burnout level and empowerment; iv) To associate selected background variable with the variables under study. A quantitative approach was adopted with comparative survey design was used the population being staff nurses both from government and private hospitals. Tools used were the Conditions of Work Effectiveness Questionnaire - CWEQ; Psychological Empowerment Scale; Nurse Manager's Action Scale and Maslach Burnout Inventory - the results showed maximum nurses were females $80 \%$ with a mean age of $29(70 \%)$ and $100 \%$ were full time employees. Maximum nurses had 4.5 years of experience (63\%) and $87.5 \%$ of them were working in the acute ward for 2.5 months. Maximum 94\% were diploma holder. Maximum nurses had Good level of leadership quality (50\%). Maximum nurses had moderate level of burnout (90\%). The empowerment level among the staff nurses was good with $50 \%$ There were no significant changes among government and private hospital staff nurses on burnout, empowerment and leadership. There was correlation between leadership and empowerment as the $p$ value was 0.000. Association was found with age and years of experience with the findings. Thus we should try and decrease the burnout by shifting the staff to another ward every 3 to 6 months. We can conduct in-service regarding the empowerment of women to increase their level of empowerment. Regular yoga classes can be included to reduce their stress level.
\end{abstract}

Keywords: Empowerment; leadership; burnout; Private and Government staff nurses

\section{Introduction}

Every client admitted to the hospital expects the maximum services are rendered to them, since they pay a large amount of money towards the health and welfare. The hospital services are similar to any other business as we too cater for various services along with health care keeping in view the value system and technological advancement. It becomes the nurses' duty to deliver the services round the clock with all the stress and strain of the profession. Thus they have to work in the surrounding which is stressful or non congenial.

Leadership is a process by which one person influences others and inspires, motivates and directs their activities to achieve group or organizational goals. The nurse must possess some leadership qualities in order to face the stress of the profession and also to achieve their targets or goal.

Empowerment is a process in which the workers are given full freedom both physically and psychologically to make decisions that will help in betterment of client's health and cut down their cost on hospitalization.

Burnout has been defined as a dilemma between oneself and their work.

To curb the nurses' turnover the condition of the work setup has to be made more professional friendly which will also help us to find good and faithful new comers. The nurse's leadership quality and power of empowerment can play an important role in the work environment. Leadership quality among nurses is an essential organizational element for providing excellent nursing care. Thus the necessity to research on this aspect was felt by the researcher.

\section{Material and Methods}

Objectives

1) To assess the leadership behaviour, burnout and empowerment level among staff nurses

2) To compare the leadership behaviour, burnout level and empowerment level between the nurses from government and private hospital

3) To assess the correlation between the leadership behaviour, burnout level and empowerment.

4) To associate selected background variable with the variables under study

\section{Methodology}

The approach to research is quantitative and comparative survey design.

The population are the nurses of acute wards from both government and private hospitals. 


\section{International Journal of Science and Research (IJSR) \\ ISSN (Online): 2319-7064 \\ Index Copernicus Value (2013): 6.14 | Impact Factor (2015): 6.391}

The samples are the acute ward nurses from government and private hospitals of Pune city.

The sample size is 50 each from private and government hospitals.

Simple random sampling by lottery system without replacement was used..

Pilot study was conducted in the following settings:

Government - Armed Forces hospitals and Ordinance Hospital,

Private - Medi-point Hospital, Bharati Hospital, and Ratna Memorial Hospital

The variables under study are:

Independent variable - Leadership behaviour,

Dependent Variables - Empowerment and Burnout level

Inclusion criteria:

Nurses of acute wards and who were available for the study on the day it was conducted.

Nurses who had undergone recognised training and have an experience of minimum six month in the clinical field.

\section{Exclusion criteria:}

Nurses who do not wish to take part in the study and have more than 10 years of services

\section{Hypothesis:}

$\mathrm{H}_{1}$-There will be correlation between empowerment, leadership behaviour and burnout among nurses.

\section{Limitation:}

The study is limited to only acute wards staff nurses with a maximum experience of 10 years in hospital.

Tools:

- Section I - Demographic Data (6 questions)

- Section II

a)Conditions of Work Effectiveness Questionnaire CWEQ

b) Psychological Empowerment Scale

c) Nurse Manager's Action Scale - Staff nurses' perceptions of nurse managers leadership behaviour and

d)Maslach Burnout Inventory - A standardized instrument - Used only the emotional exhaustion scale.

\section{Validation}

The tool was validated from 9 experts from the field of Nursing, education and management and tools were corrected as suggested.

\section{Reliability}

The reliability of the tools were established with cronbach's alpha test on 5 samples. All tools under study were reliable. The values for the test were $0.89,0.71,0.81$ and 0.92 respectively for the tools of section II - condition of work effectiveness, psychological empowerment, nurse managers action and burnout inventory respectively.

\section{Data Collection}

Formal permission obtained from the respective hospital head, followed by nursing head and the acute ward in-charge nurses. All the protocol of the research study followed. The tool and the study objectives were explained to the subject. The tools were administered during their break time which took 20 to 30 minutes. The data was analysed using SPSS Version 17 .

\section{Results}

The demographic data showed maximum nurses were females $80 \%$ with a mean age of $29(70 \%)$ and $100 \%$ were full time employees. Maximum nurses had 4.5 years of experience $(63 \%)$ and $87.5 \%$ of them were working in the acute ward for 2.5 months. Maximum 94\% were diploma holder.

Maximum acute ward nurses had Good level of leadership quality $(50 \%)$ and medium level of leadership quality (47.5\%). The mean and SD was $40.35 \pm 7.45$.

Maximum nurses had moderate level of burnout (90\%). The mean and SD was $44.45 \pm 8.59$.

The empowerment level among the staff nurses was good in $50 \%$ and average among $47.5 \%$. The mean and SD was $73.17 \pm 12.95$.

On comparison of leadership quality empowerment and burnout there were no significant changes among government and private hospital staff nurses.

There was correlation between leadership and empowerment as the $p$ value was 0.000

There was an association between age and years of experience with burnout.

\section{Discussion}

Based on the pilot study it is found that there is not much difference among government and private hospital staff nurse work pattern or the empowerment and leadership. There is correlation between leadership and empowerment but no correlation with burnout. As the study is done on 50 samples each due to time constraints but when performed over 400 samples may be we find some relations among the variables under study. Thus the hypothesis is partially correct. This is an evidence for the clinical nurses that private nurses are in equal power with government staff in all aspects. Many more studies can be conducted in different setting at various cities. We can include in the nursing education, the empowerment aspect of the nurses.

\section{References}

[1] Aiken, L.H., Clarke, S.P., Sloane, D.M., Sochalski, J., \& Silber, J.H. (2002). Hospital nurse staffing and patient 


\section{International Journal of Science and Research (IJSR) \\ ISSN (Online): 2319-7064}

Index Copernicus Value (2013): 6.14 | Impact Factor (2015): 6.391

mortality, nurse burnout, and job dissatisfaction. JAMA, 288(16), 1993.

[2] Conger, J.A. \& Kanungo, R.N. (1988). The empowerment process: integrating theory and practice, Academy of Management Review, 13(3), 471482.

[3] Ellefsen, B. \& Hamilton, G. (2000). Empowered nurses? Nurses in Norway and the USA compared. International Nursing Review, 47, 106120.

[4] Greco, P., Laschinger, H.K.S., Wong, C. (2006). Leader empowering behaviors, staff nurse empowerment and work engagement/burnout. Nursing Research, 19(4), 4156.

[5] Kanai Pak, M. (2007a) Critical issues related nurses' work environment in Japan. The Japanese Journal of Nursing Research, 40(7), 6170.

[6] Laschinger, H.K.S., Wong, C., McMahon, L., Kaufmann, C.M. (1999). Leader behavior impact on staff nurses empowerment, job tension and work effectiveness. Journal of Nursing Administration, 29(5), 2839.

[7] Masako Kanai Pak Ph. D Dissertation on leadership behaviors that mitigate burnout and empower Japanese nurses. 